\title{
IOT-based Auto-Payment of Toll Tax
}

\author{
Sukriti Singh \\ VIT University
}

\begin{abstract}
Autopayment of toll tax is designed to solve the congestion problems faced around tollgate. The system works on the principal of RFID identification cards, wherein a user has to get a card(RFID) from the central authority which stores the information about the user like name, contact number, registration number, vehicle type etc. This enables the user to use these government assigned cards to pay the toll taxes for faster checkout time. The system is designed to automatically calculate the amount of toll tax for a particular vehicle based on the type of the vehicle. The user has access to a web interface where he can use the querying tools which will tell him about his commute and the number of funds left on his card. The web interface also facilitates in adding funds to the card so that the user does not have to go to the authorized center for recharging his card.
\end{abstract}

\section{Keywords}

Arduino Uno, RFID Reader, Automation, IOT, LCD, EM18, MySQL.

\section{INTRODUCTION}

Auto Payment of Toll Tax is a system used to simplify the toll tax payment process. Generally, every car that passes the toll gateway has to pay a tax for maintenance of the road and for this, an employee is hired for collecting the same. Cars have to stop for paying the tax and the exchange takes time, especially when there is a change involved(which almost always is the case). To avoid this time, we have automated the toll tax payment system.

In this system, we have dedicated lanes for the vehicle owners who have the RFID card issued by a central body. People who travel a lot via the toll gateway can opt for this card which basically works like a digital wallet wherein a person can add money as per his travel requirements. Therefore if a person possesses such a card, the money will be deducted from his digital wallet when he crosses the toll booth, hence avoiding the need to stop at the toll booth for the transaction process. In this system, all the toll-taxes are being collected by the central body who will distribute the income to the respective owners which are identified by the primary key in the database. By doing this, we ensure that the people can use the same RFID for all the toll taxes in the country hence carry only one card.

\section{LITERATURE SURVEY}

Considering the present toll collection system where each vehicle has to stop and pay taxes. Suppose the manual toll collection system is very efficient then for one vehicle to stop and pay taxes total time taken is 60 seconds. And suppose 100 vehicles cross the toll plaza. Then, time taken by 1 vehicle with 60 second average stop in a month is: $60 \times 30=1800$ seconds

Yearly total time taken $=1800 \times 12=216200$ seconds $=6.0$ hours.

Assuming cost of 1-liter fuel $=$ Rs 75 as given in the Table 1 .

\author{
Pankul Garg \\ VIT University
}

Table 1. Fuel Consumption and Amount

\begin{tabular}{|l|l|l|}
\hline Vehicles & $\begin{array}{l}\text { Fuel } \\
\text { Consumption }\end{array}$ & Amount \\
\hline 1 & 1 lit. & $75 /-$ Rs \\
\hline 3600000 & 3600000 & $270,000,000$ \\
\hline
\end{tabular}

Table 2. Vehicles Passed away from Toll Booth in 1 year

\begin{tabular}{|l|l|l|l|}
\hline Vehicles & Days & $\begin{array}{l}\text { No } \\
\text { Tollbooth }\end{array}$ & $\begin{array}{l}\text { Petrol } \\
\text { Consumed }\end{array}$ \\
\hline 36000 & $30 * 12$ & 1 & 216000 \\
\hline 3600000 & $30 * 12$ & 1 & 21600000 \\
\hline
\end{tabular}

On average each vehicle that passes through the toll plaza has to wait 6.0 hours in engine start condition yearly. As per Table 2 The figure is staggering if on an average we take 100 vehicles pass through the toll plaza each day, then yearly 36000 vehicles pass through the toll plaza. And each year 36000 vehicles just stand still for 6.0 hours in engine start condition thereby aiding pollution and wasting fuel and money.

Total cost of fuel consumed by

36,00000 vehicles $=75 \times 36,00,000=$ Rs. $270,000,000 /-$

The above is the money wastage under the consideration that the vehicle stops for 60 second at the toll system, and 100 vehicles pass through the toll plaza each day and there are 100 toll plazas. These figures are all in minimum.

\section{MODULES}

\subsection{Working of EM18}

The module radiates $125 \mathrm{KHz}$ through its coils and when a $125 \mathrm{KHz}$ passive RFID tag is brought into this field it will get energized from this field. These passive RFID tags mostly consist of CMOS IC EM4102 which can get enough power for its working from the field generated by the reader. By changing the modulation current through the coils, tag will send back the information contained in the factory programmed memory array. We will be using this RFID module to get the unique Identification number of the passive RFID tag.

\subsection{Interfacing EM18 with Arduino Uno: -}

We will be using RS232 data format to transmit the data from the module to Arduino because the serial output can be directly interfaced with the arduino board I.e easier to read.

\subsection{MySQL Query Operations: -}

After getting the input from the arduino board we have to perform MySQL operations for which we will be needing another language I.e processing as arduino does not support MySQL operations.

Processing will enable us to get the input from the serial port and then perform the MySQL operations with ease. As 
arduino does not support MySQL queries and as the information that can be stored on the passive RFID card is too low, we are going to use processing to add data in the MySQL servers. Processing is an open source language which support MySQL queries as well as it can read the serial data input from the arduino board which will solve our problem efficiently.
This is one of the solutions and we are still looking for others as this step i.e sorting and fetching data from the database will be the most time consuming in our entire project hence it should be dealt with fastest yet reliable way.

\section{FIGURES}

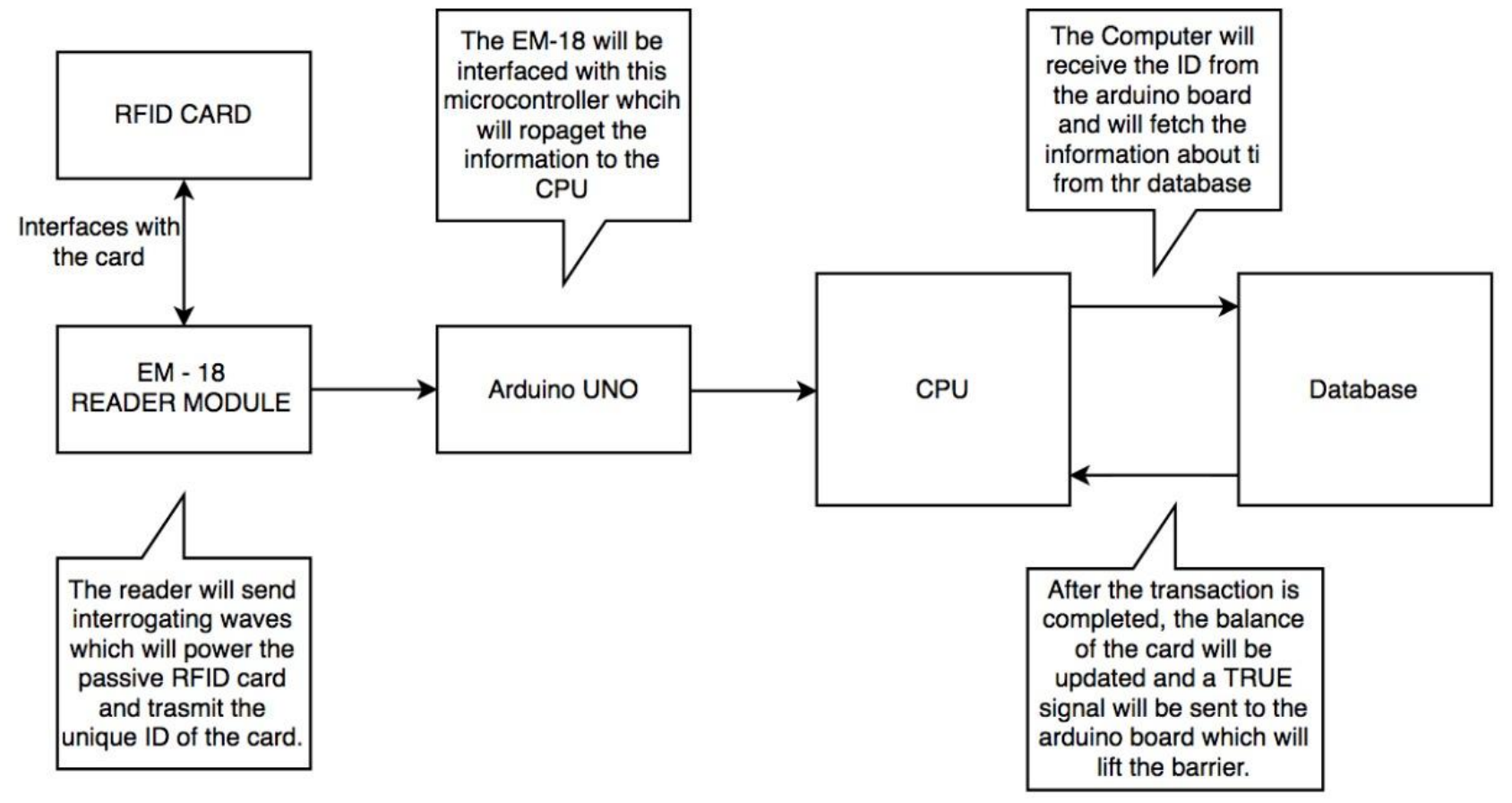

Fig 1. Computing Design of the Proposed System 


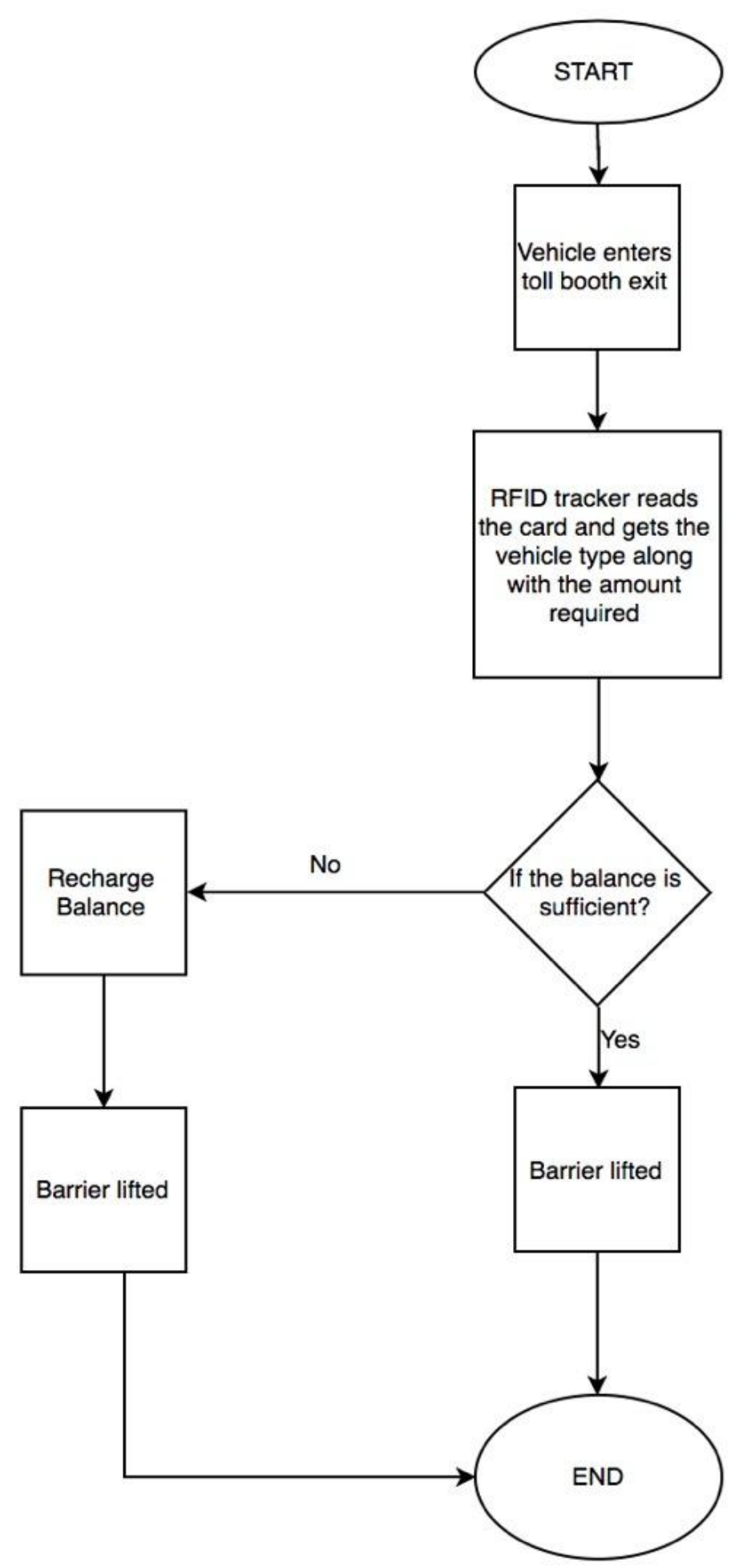

Fig 2: Design Flowchart

\section{COMPONENTS}

\subsection{RFID Reader}

In order for an RFID system to function, it needs a reader, or scanning device, that is capable of reliably reading the tags and communicating the results to a database. A reader uses its own antenna to communicate with the tag. When a reader broadcasts radio waves, all tags designated to respond to that frequency and within range will respond. A reader also has the capability to communicate with the tag without a direct line of sight, depending on the radio frequency and the type of tag (active, passive, or semi passive) used. Readers can process multiple items at once, allowing for increased read processing times. 


\subsection{Arduino Uno}

An Arduino is a microcontroller motherboard. A microcontroller is a simple computer that can run one program at a time, over and over again. It is very easy to use. Micro controller senses the signal given from switches and decides the mode of operation i.e. recharge mode or toll collection mode. It fetches data from memory location and send it to output device, the LCD.

We are using arduino uno for our system because our system will be designed to do a set of specific repetitive tasks and arduino is best used for simple repetitive tasks. An alternative for the arduino could have been the Raspberry pi but it is best used when you need a full-fledged computer which is not exactly needed in the case of our project.

\subsection{RFID Tag : -}

An RFID tag, or transponder, consists of a chip and an antenna. A chip can store a unique serial number or other information based on the tag's type of memory, which can be read-only, read-write, or write once read-many(WORM). The antenna, which is attached to the microchip, transmits information from the chip to the reader. Typically, a larger antenna indicates a longer read range. The tag is attached to or embedded in an object to be identified, such as a product, case, or pallet, and can be scanned by mobile or stationary readers using radio waves.

\subsection{Liquid Crystal Display: -}

It consists of Liquid Crystal display (LCD). The display is various messages like valid card, invalid card, access allowed, manual access etc. We are going to use $16 \times 2$ alphanumeric display.

\section{Computing Design}

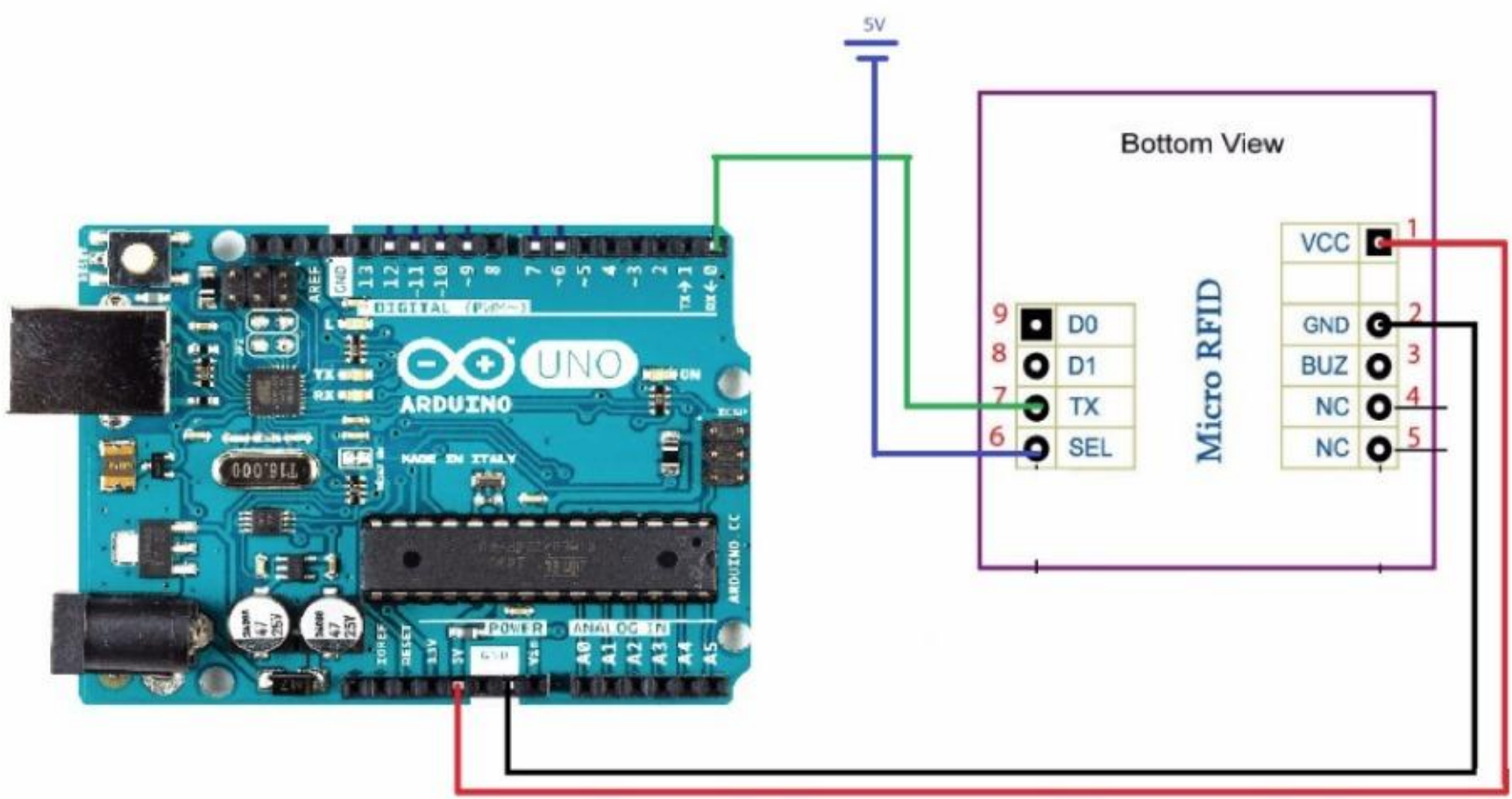

Fig 2: Arduino RFID Interfacing

\section{EXPERIMENTAL RESULT AND \\ ANALYSIS}

Considering a scenario where an average person spends about 5 seconds on the toll booth if he has issued an RFID card as a part of our proposed system, we calculated the average fuel and money spent over an year if the same sample population size of 36000 people a year.

Considering an average person spends about 5 seconds on the toll booth, the average petrol used by a car in a year comes out to be 0.5 liters.

Table 3. Fuel Consumption by the population with proposed system

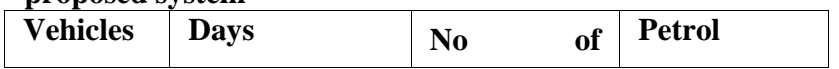

\begin{tabular}{|l|l|l|l|}
\hline & & Tollbooth & Consumed \\
\hline 36000 & $30 * 12$ & 1 & 18000 \\
\hline 36000 & $30 * 12$ & 100 & 1800000 \\
\hline
\end{tabular}

As per the data in the Table 3, we can calculate the amount of money spent in one year by $36,00,000$ vehicles $=75 \mathrm{x}$ $1800000=$ Rs. $1350,00,000 /-$

The above calculations show a massive $95 \%$ decrease in the amount of fuel consumed and the money spent on the same in a year.

\section{DESIGN ALTERNATIVES}

\subsection{Alternatives for Arduino Uno: -}

Raspberry Pi: Although it has a large on chip memory, raspberry pi is more useful when a full-fledged computer is 
needed and when multiple tasks need to be performed. However, in the proposed system, only a set of steps need to be performed repeatedly and arduino Uno is suitable for that. Moreover, raspberry pi is more expensive then arduino uno and as we don't have those many functionalities to implement, arduino uno is the right choice for this particular system.

\subsection{Alternatives for RFID Reader (Barcode \\ Reader): -}

RFID is 15-20 times faster than manual and barcode processes. Some companies experience a $95 \%$ reduction in time using RFID. One advantage of RFID is that the technology doesn't require line of sight. RFID tags can be read as long as they are within range of a reader. If a label is ripped or soiled or has fallen off, there is no way to scan the item, and standard barcodes identify only the manufacturer and product, not the unique item. RFID readers don't require human involvement to collect data whereas most barcode scanners require a hum to operate.

\subsection{Alternatives for RFID Reader (RuBee) : -}

Rubee is a form of radio-frequency identification and uses low frequency radio waves and active transceivers that communicate peer-to-peer. RuBee systems create a large readfield, and changes within that field enable tags to communicate. RuBee is ideal for applications that involve tracking metal object or those in an environment containing a lot of metal. It has largely been used for weapons tracking for this reason, at it performs better than other types of RFID for such an application.

\section{CONCLUSION}

The biggest advantage of this technology is the opportunity to eliminate congestion in tollbooths, especially during festive seasons when traffic tends to be heavier than usual. It is also a method by which to curb complaints from motorists regarding the inconveniences involved in manually making payments at the tollbooths. The benefits for the motorists would include fewer or shorter queues at toll plazas by increasing toll booth service turnaround rates, faster and more efficient service (no exchanging toll fees by hand), the ability to make payments by keeping a balance on the card itself or by loading a registered credit card, the use of postpaid toll statements (no need to request for receipts).

Other general advantages for the motorists include fuel savings and reduced mobile emissions by reducing or eliminating deceleration, waiting time, and acceleration. Meanwhile, for the toll operators, the benefits include Lowered toll collection costs, better audit control by centralized user accounts, expanded capacity without building more infrastructures, everyday thousands of people go past the toll tax booth paying toll tax.

Currently the toll payment system is manual, so the drivers are made to use a manual system by which payment is done by cash by hand method to pass across the toll plaza gate.
Manual process is very time consuming, the drivers have to wait in row for long time for crossing the toll plaza. During their wait, time and fuel of vehicle is highly consumed.

To extend this project further we are also planning to develop an android and IOS application which is interfaced with all payment method to recharge the card online. The RFID card which is used in this project (LF RFID) can sense cards up to $10 \mathrm{~cm}$ i.e. vehicle will still have to stop and swipe their respective RFID cards for the checkout to process. This can be further improved by using UHF RFID which can detect cards from a distance of 12 meters further facilitating in the easier and faster checkout without the driver need to wait for the payment procedure.

\section{ACKNOWLEDGMENTS}

We would like to thank my guide Prof $\mathrm{R}$ Maheshwari who supported us through the different phases of the project. Also, we are grateful to VIT University for providing us the resources which led to successful implementation of the project.

\section{REFERENCES}

[1] M. Deriche, M. Mohandes "A Hybrid RFID-LPR System for Vehicle Access Control during Pilgrimage Season in Saudi Arabia", International MultiConference on Systems, Signals and Devices 2012

[2] Elipe.NageswaraRao, G.Tirumala Vasu, N.G.N.Prasad, kranthi Kumar, V.Rajesh, "Payment Automation at TollGate Using RFID and SMS Alert", IJCET Vol.2,SP1,Dec.2011.

[3] Yanbo Wu, Quan Z. Sheng, "Modeling Object Flows from Distributed and Federated RFID Data Streams for Efficient Tracking and Tracing".

[4] Janani Krishnamurthy, Nitin Mohan, Rajeshwari Hegde, "Automation of Toll Gate and Vehicle Tracking", International Conference on Computer Science and Information Technology 2008.

[5] Kenneth Jayala, "8051 Microcontroller Architecture", programming and application.

[6] Muhammad Ali Mazidi, Janice Gillispie Mazidi "The 8051 Microcontroller and Embedded Systems”, Pearson Education.

[7] Kamran Ahsan, Hanifa shah, Paul kingston "RFID Applications: An Introductory and Exploratory Study "

[8] Satyasrikanth P,Mahaveer Penna, Dileep Reddy Bolla "AUTOMATIC TOLL COLLECTION SYSTEM USING RFID"

[9] Kun Liu, Long-jiang Dongab "Research on Cloud Data Storage Technology and Its Architecture Implementation"

[10] Rakhi Kalantr, Anand Parekar, Akshay Mohite,Rohan Kankapurkar "RFID Based Toll Collection System" 